\title{
Breaking dormancy of Stylosanthes humilis seeds with selenium compounds
}

\author{
Frank James Araújo Pinheiro ${ }^{\dagger}$, Raimundo Santos Barros*, Tales Graciano Coelho \\ and Braulio Maia de Lana Souza
}

Depto. de Biologia Vegetal, Universidade Federal de Viçosa, Viçosa 36570-000, MG, Brazil

\begin{abstract}
The soluble selenium (Se) compounds selenic acid, selenious acid, selenium dioxide, selenium tetrachloride, selenomethionine, selenourea, sodium selenate and sodium selenite broke the dormancy of scarified seeds of Townsville stylo (Stylosanthes humilis HBK). Given the chemical diversity of all these molecules, it could be deduced that Se may act as a dormancybreaking agent of Townsville stylo seeds. Se-stimulated seeds produced great amounts of both ethylene and 1-aminocyclopropane-1-carboxylic acid, which correlated with the process of germination. As specific inhibitors of ethylene biosynthesis and action largely depressed this Se-stimulated germination, it was concluded that Se broke dormancy by triggering ethylene production by the seeds.
\end{abstract}

Keywords: dormancy, ethylene, germination, seeds, selenium, Stylosanthes humilis, Townsville stylo

\section{Introduction}

In plant cells, the relationship between selenomethionine (SeM) and ethylene is complex. As a singlet oxygen quencher and an inhibitor of lipid peroxidation, this selenoaminoacid acts as a cell protectant, and prevents ethylene generation by lipid peroxidation/free radical formation. Thus, ethylene formation was inhibited and the membrane system was well preserved in cells of Spirodela oligorrhiza, an aquatic angiosperm, treated with cupric ions in a SeM-containing medium. In the absence of SeM,

\footnotetext{
*Correspondence

Fax: + 553138992580

Email: rsbarros@ufv.br

${ }^{\dagger}$ Present address: Depto. de Biologia, Campus do Paricarama, Universidade Federal de Roraima, 69310-270 Boa Vista, RR, Brazil
}

ethylene production was high, and cell membranes showed a high degree of damage (Mattoo et al., 1986). In contrast, in $\mathrm{Cu}^{2+}$ - treated leaf discs of tobacco, $\mathrm{SeM}$ stimulated ethylene production through the 1-aminocyclopropane-1-carboxylic acid (ACC) pathway (Mattoo et al., 1992).

Freshly harvested seeds of the annual tropical forage legume Townsville stylo (Stylosanthes humilis HBK) exhibit relatively hard covers and also an endodormancy that is gradually released during postharvest storage. After $\geq 12$ months of dry storage, seeds are fully non-dormant and germinable (Vieira and Barros, 1994). Ethylene is required for the germination of scarified seeds (Ribeiro and Barros, 2004, 2006), and thus, any factor inducing ethylene production may lead to the breaking of dormancy. Based on the action of SeM on plant tissues described above, Barros and Freitas $(2000,2001)$ succeeded in breaking dormancy of Townsville stylo seeds with the application of this Se-aminoacid. As this response was blocked by 2-aminoethoxyvinylglycine (AVG), an inhibitor of ACC synthase, and by cobaltous ions, which inhibit ACC oxidase, the authors suggested that SeM induced ethylene biosynthesis through the ACC pathway. During this work, $\mathrm{SeO}_{2}$ (obtained by oxidizing elemental Se with nitric acid; Merck \& Co., 1989) and unidentified Se compounds (obtained by dissolving Se with hydrochloric acid) also broke dormancy of Townsville stylo seeds (Barros and Freitas, unpublished observations). Thus, it was likely that dormant seeds of this species respond not only to SeM, but also to several other Se compounds, a hypothesis that was examined in the present work.

\section{Materials and methods}

\section{Plant material and general conditions}

Seeds were harvested from Townsville stylo plants cultivated in $3.0 \mathrm{dm}^{3}$ plastic pots in a greenhouse in Viçosa $\left(20^{\circ} 45^{\prime} \mathrm{S}, 42^{\circ} 15^{\prime} \mathrm{W}\right)$, Minas Gerais State, Brazil, 
and kept in the laboratory under dry conditions. Dormant seeds used in this study had been stored $\leq 4$ months after harvest, and non-dormant seeds used were $\geq 12$ months old. In this way, seeds of several postharvest ages, i.e. with different degrees of dormancy, were available for the assays. Seeds were freed from their husks, scarified with fine sandpaper, sterilized with $0.5 \%(\mathrm{w} / \mathrm{v}) \mathrm{NaOCl}$ for $10 \mathrm{~min}$ and thoroughly washed with distilled water. Afterwards, they were infiltrated by partial vacuum with test solutions at $\mathrm{pH} 7.0$, which also contained $0.05 \%(\mathrm{v} / \mathrm{v})$ Tween 80 . Fifty seeds were then transferred to $9 \mathrm{~cm}$ diameter Petri dishes, or 25 seeds were placed in $25 \mathrm{ml}$ Erlenmeyer flasks with two layers of Whatman No. 1 filter paper, and imbibed with $10 \mathrm{ml}$ or $2 \mathrm{ml}$ test solution, respectively. Germination tests were conducted in the dark at $30^{\circ} \mathrm{C}$ in a growth chamber (Forma Scientific Inc., Ohio, USA). Seeds with a radicle c. $3.0 \mathrm{~mm}$ long were considered as germinated. Daily germination counts were carried out for $5 \mathrm{~d}$, unless otherwise stated.

\section{Effect of Se compounds on seed germination}

Due to the toxicity of the Se compounds, several experiments were conducted to determine the optimal concentrations for maximal seed germination and the maximum period of time that seeds could be exposed to Se-containing solutions. Concentrations higher than the optimum and exposure times $>18-$ $24 \mathrm{~h}$ caused decreased germination; rootlets showed stunted growth, tips became brownish or darkened, and hypocotyls were severely shortened. Therefore, in all experiments (germination inhibition, ethylene and ACC determination), the optimal Se concentrations (see below) and an $18 \mathrm{~h}$ exposure time were used. Subsequently, seeds were washed thoroughly with distilled water and transferred to a new Petri dish or Erlenmeyer flask containing fresh control or other treatment media. Eight Se compounds (SigmaAldrich, St Louis, Missouri, USA) were tested: selenic acid $\left(\mathrm{H}_{2} \mathrm{SeO}_{4}\right), 1.0 \mathrm{mM}$; selenious acid $\left(\mathrm{H}_{2} \mathrm{SeO}_{3}\right)$, $0.6 \mathrm{mM}$; selenium dioxide $\left(\mathrm{SeO}_{2}\right), 0.2 \mathrm{mM}$; selenium tetrachloride $\left(\mathrm{SeCl}_{4}\right), 0.2 \mathrm{mM}$; seleno-L-methionine (SeM; $\mathrm{C}_{5} \mathrm{H}_{11} \mathrm{NO}_{2} \mathrm{Se}$ ), $1.0 \mathrm{mM}$; selenourea (SeU; $\left.\mathrm{CH}_{4} \mathrm{~N}_{2} \mathrm{Se}\right), 1.0 \mathrm{mM}$; sodium selenate $\left(\mathrm{Na}_{2} \mathrm{SeO}_{4}\right)$, $2.0 \mathrm{mM}$; and sodium selenite $\left(\mathrm{Na}_{2} \mathrm{SeO}_{3}\right), 0.2 \mathrm{mM}$ (all compounds shown with their optimal concentrations eliciting germination). Seed viability (and also Se toxicity) in the conditions employed was tested following the main assays. After $5 \mathrm{~d}$ of seed incubation, solutions were replaced by $100 \mathrm{mM}$ thiourea (Ballard and Buchwald, 1971).

Germination inhibition of Se-treated seeds was attempted in Petri dishes with $0.1 \mathrm{mM}$ AVG, $1.0 \mathrm{mM} \mathrm{Co}^{2+}$ [provided as $\mathrm{Co}\left(\mathrm{NO}_{3}\right)_{2}$ ] or $0.5 \mathrm{mM}$ silver thiosulphate, which was freshly prepared immediately before use (Reid et al., 1980). Dormant seeds were exposed to combined solutions of Se compounds plus the inhibitors for $18 \mathrm{~h}$. After washing, they were supplied with the inhibitor solution only. In order to revert the action of ethylene inhibitors, after exposing seeds to Se compounds plus the inhibitors, the seeds were transferred to fresh solutions of AVG plus $1.0 \mathrm{mM}$ ACC, $\mathrm{Co}^{2+}$ plus $0.1 \mathrm{mM}$ 2-chloroethylphosphonic acid (CEPA), or a $10 \mathrm{mM} \mathrm{HCl}, \mathrm{pH} 2.0$, solution.

\section{Ethylene quantification}

Erlenmeyer flasks $(25 \mathrm{ml})$ containing 25 seeds, two layers of filter paper and $2.0 \mathrm{ml}$ medium were stoppered with rubber serum caps and stored in a growth chamber at $30^{\circ} \mathrm{C}$. Germination was recorded at intervals, and a $1.0 \mathrm{ml}$ sample of flask atmosphere was taken with a gas-tight syringe for ethylene determination (Saltveit and Yang, 1987). Flasks were then unstoppered, and their atmospheres exhausted in a fume-hood. Flasks were stoppered again, and the process repeated until the end of the experiment. Gas samples were injected into a chromatograph (HewlettPackard 5890, series II) equipped with a flame ionization detector and a stainless-steel column packed with Porapack-N, 80-100 mesh. Chromatographic conditions were as described in Ribeiro and Barros (2006).

\section{ACC determination}

Samples of 250 seeds per $15 \mathrm{~cm}$ diameter Petri dish with two layers of filter paper and $15 \mathrm{ml}$ of test solution were incubated in a growth chamber at $30^{\circ} \mathrm{C}$. Samples were taken at intervals for ACC determination, according to Gallardo et al. (1994) with few modifications. Germination in the Se-compounds was monitored in parallel in $9.0 \mathrm{~cm}$ Petri dishes. Seeds were thoroughly washed with distilled water, paperdried, immersed in liquid nitrogen and kept at $-20^{\circ} \mathrm{C}$ until analysis. Seeds were ground in a mortar and pestle with $80 \%$ ethanol plus polyvinylpyrrolidone (5\% mass/volume). Following filtration, the extract was centrifuged $\left(28,000 \mathrm{~g}, 4^{\circ} \mathrm{C}, 20 \mathrm{~min}\right)$, and the supernatant was roto-evaporated to dryness and the residue resuspended in $4.0 \mathrm{ml}$ of distilled water. Half of the extract was taken for free ACC analysis by chemical conversion to ethylene (Lizada and Yang, 1979). The other half was used for the determination of total (free plus conjugated) ACC. This portion of the extract was hydrolysed with $\mathrm{HCl}(2 \mathrm{~N})$, at $100^{\circ} \mathrm{C}$ for $3 \mathrm{~h}$. Following hydrolysis, the extract was neutralized with $\mathrm{NaOH}$, roto-evaporated until dryness and resuspended in water for ACC determination. 


\section{Statistical design}

The statistical design of the assays was based on a completely randomized distribution with five replicates for germination tests in Petri dishes (50 seeds each), or ten replicates for germination and ethylene determinations in Erlenmeyer flasks (25 seeds each). Germination percentages were transformed into $\arcsin (\% \mathrm{G} / 100)^{1 / 2}$ to follow a normal distribution. For ACC quantification, four replicates $(15 \mathrm{~cm}$ Petri dishes, 250 seeds each) were assessed. Differences among means were tested according to Scott and Knott (1974) for germination assays, or by Tukey test for ethylene and ACC quantifications. Comparisons were performed at $5 \%$ significance.

\section{Results}

Of the many independent experiments, two representative ones were selected and are summarized in Table 1. The first experiment was carried out in Erlenmeyer flasks for ethylene determination, and the other in Petri dishes for ACC analysis. Results with all Se compounds were very similar, varying only in the magnitude of response. The patterns of response to all Se compounds were also similar; the results for SeUand $\mathrm{H}_{2} \mathrm{SeO}_{3}$-treated seeds were chosen as representative of all other Se-treated seeds and are illustrated in Fig. 1. All Se compounds tested relieved dormancy of Townsville stylo seeds in experiments conducted either in Petri dishes or sealed Erlenmeyer flasks (Table 1, Fig. 1).
The relationships between germination, ethylene and ACC production are shown in Fig. 1 for SeU- and $\mathrm{H}_{2} \mathrm{SeO}_{3}$-stimulated dormant seeds. Germination, ethylene and ACC production were fairly related; this holds true not only for SeU- and $\mathrm{H}_{2} \mathrm{SO}_{3}$-treated seeds, but also for seeds tested with all the other Se compounds listed in Table 1 (data not shown). The start of all these phenomena occurred earlier in untreated, non-dormant seeds than in all Se-stimulated dormant seeds. Figure 1 also shows that the germination process was slower in seeds treated with the Se compounds.

Germination of Se-stimulated seeds was depressed by AVG and $\mathrm{Co}^{2+}$, inhibitors of ethylene biosynthesis, and by $\mathrm{Ag}^{+}$, an inhibitor of ethylene action (Fig. 2A). The involvement of ethylene in the phenomenon of dormancy breakage was further supported by the almost complete restoration of germination brought about by transferring the inhibited seeds to media containing the inhibitors plus ethylene-producing compounds, i.e. AVG plus ACC, $\mathrm{Co}^{2+}$ plus CEPA or, in the case of $\mathrm{Ag}^{+}$-inhibited seeds, to an $\mathrm{HCl}$ solution (Fig. 2B).

\section{Discussion}

The only chemical characteristic common to all compounds breaking dormancy of Townsville stylo seeds (Table 1) is the presence of Se atoms in the molecule. Other Se compounds tested in a complementary experiment (diselenium dichloride, selenium oxychloride, selenium cystine, selenoethionone and selenopurine, data not shown) also broke

Table 1. Columns 2 and 3: germination (5 replicates) and ethylene production (10 replicates) for dormant Stylosanthes humilis seeds treated with Se compounds contained in sealed Erlenmeyer flasks. Both parameters were assayed $72 \mathrm{~h}$ from the start of seed incubation. Columns 4-6: germination and maximal accumulation of 1-aminocyclopropane-1-carboxylic acid (ACC) for dormant seeds treated with Se compounds and contained in Petri dishes (free ACC of non-dormant seeds was determined at $24 \mathrm{~h}$ and was not comparable statistically with the other treatments; free ACC for Se-treated seeds was assayed at $36 \mathrm{~h}$ and total ACC analysis for all treatments content was obtained at $72 \mathrm{~h}$ ). See text and Fig. 1 for further details

\begin{tabular}{|c|c|c|c|c|c|}
\hline \multirow[b]{2}{*}{ Compound } & \multirow[b]{2}{*}{ Germination (\%) } & \multirow{2}{*}{$\begin{array}{c}\text { Ethylene } \\
\left(\text { pmol seed }^{-1}\right)\end{array}$} & \multirow[b]{2}{*}{ Germination (\%) } & \multicolumn{2}{|c|}{ ACC $\left(\mathrm{pmol} \mathrm{seed}^{-1}\right)$} \\
\hline & & & & Free & Total \\
\hline $\mathrm{H}_{2} \mathrm{SeO}_{4}$ & $74.8 \mathrm{~d}$ & $217.5 \mathrm{c}$ & $73.2 \mathrm{~b}$ & $97.6 \mathrm{c}$ & $384.5 \mathrm{~cd}$ \\
\hline $\mathrm{H}_{2} \mathrm{SeO}_{3}$ & $72.8 \mathrm{~d}$ & $143.6 \mathrm{~d}$ & $70.0 \mathrm{~b}$ & $89.2 \mathrm{~cd}$ & 293.1 de \\
\hline $\mathrm{SeO}_{2}$ & $78.4 \mathrm{c}$ & $196.0 \mathrm{c}$ & $74.8 \mathrm{~b}$ & $92.3 \mathrm{~cd}$ & $405.5 \mathrm{~cd}$ \\
\hline $\mathrm{SeCl}_{4}$ & $84.0 \mathrm{~b}$ & $214.5 \mathrm{c}$ & $77.2 \mathrm{a}$ & $122.1 \mathrm{C}$ & $555.0 \mathrm{bc}$ \\
\hline SeM & $70.4 \mathrm{~d}$ & $285.6 \mathrm{a}$ & $68.4 \mathrm{~b}$ & $313.9 \mathrm{a}$ & $1030.1 \mathrm{a}$ \\
\hline SeU & $90.0 \mathrm{~b}$ & $260.5 \mathrm{~b}$ & $84.8 \mathrm{a}$ & $113.3 \mathrm{c}$ & $662.3 \mathrm{~b}$ \\
\hline $\mathrm{Na}_{2} \mathrm{SeO}_{4}$ & $71.6 \mathrm{~d}$ & $215.3 c$ & $79.2 \mathrm{a}$ & $174.0 \mathrm{~b}$ & $648.9 \mathrm{~b}$ \\
\hline $\mathrm{Na}_{2} \mathrm{SeO}_{3}$ & $80.0 \mathrm{c}$ & $194.1 \mathrm{c}$ & $81.2 \mathrm{a}$ & $86.8 \mathrm{~cd}$ & $469.1 \mathrm{bc}$ \\
\hline Dormant control & $17.2 \mathrm{e}$ & $43.5 \mathrm{e}$ & $10.0 \mathrm{c}$ & $21.1 \mathrm{e}$ & $150.0 \mathrm{e}$ \\
\hline Non-dorm. control & $97.6 \mathrm{a}$ & $242.9 \mathrm{~b}$ & $84.0 \mathrm{a}$ & 59.1 & $467.1 \mathrm{~cd}$ \\
\hline
\end{tabular}

$\mathrm{H}_{2} \mathrm{SeO}_{4}$, Selenic acid; $\mathrm{H}_{2} \mathrm{SeO}_{3}$, selenious acid; $\mathrm{SeO}_{2}$, selenium dioxide; $\mathrm{SeCl}_{4}$, selenium tetrachloride; SeM, seleno-L-methionine; $\mathrm{SeU}$, selenourea; $\mathrm{Na}_{2} \mathrm{SeO}_{4}$, sodium selenate; $\mathrm{Na}_{2} \mathrm{SeO}_{3}$, sodium selenite; non-dorm., non-dormant.

Means followed by different letters within a column are statistically different at the $5 \%$ level by the Scott-Knott (germination) and Tukey (ACC, ethylene) tests. 


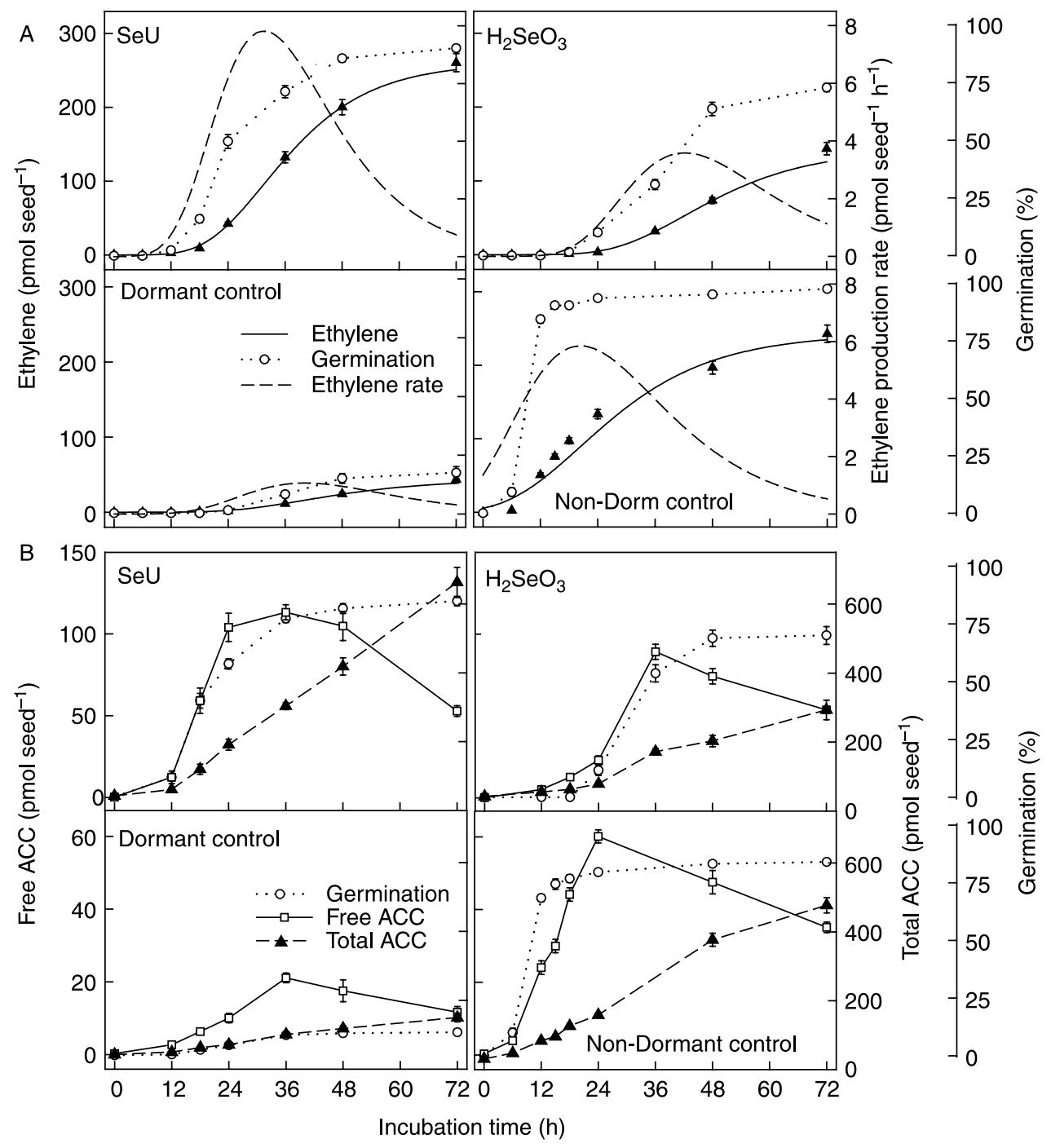

Figure 1. (A) Germination, ethylene (and rate of ethylene) production in selenourea (SeU)- and selenious acid $\left(\mathrm{H}_{2} \mathrm{SeO}\right)_{3}$-treated and untreated dormant and non-dormant Stylosanthes humilis seeds contained in sealed 25 ml Erlenmeyer flasks. Points represent means of ten replicates \pm SE. (B) Germination and 1-aminocyclopropane-1-carboxylic acid (ACC) accumulation in SeU- and $\mathrm{H}_{2} \mathrm{SeO}_{3}$-treated seeds and untreated dormant and non-dormant seeds contained in Petri dishes. Means of four replicates \pm SE. Similar patterns for each of the parameters were obtained with all other Se compounds tested (not shown); illustrative data are summarized in Table 1.

dormancy of Townsville stylo seeds, supporting these observations and conclusion. The oxidation state of Se in the various compounds studied varies from -2 to +6 ; they are organic (SeM, SeU) or inorganic; stable or unstable (most Cl-containing molecules decompose in water; Merck \& Co., 1989). Thus, it seems that Se atoms by themselves constitute the dormancy-breaking agent. Therefore, not only does selenomethionine (SeM) break seed dormancy (Barros and Freitas, 2000, 2001), but similar results were given by many other different Se compounds that do not structurally resemble SeM.
Two important differences were observed between Se-treated and non-dormant seeds. The start of germination by Se-stimulated seeds lagged behind the start of germination of non-dormant seeds, and the completion of the germination process took longer in the Se-treated group. This lag in time might be a consequence of the processes occurring between uptake and action of the Se compounds. In this regard, the responses to the various Se compounds are not the same, and small differences do exist among them; for instance, SeU-treated seeds germinated earlier than $\mathrm{H}_{2} \mathrm{SeO}_{3-}$ treated seeds (Fig. 1A). This is likely a consequence of 


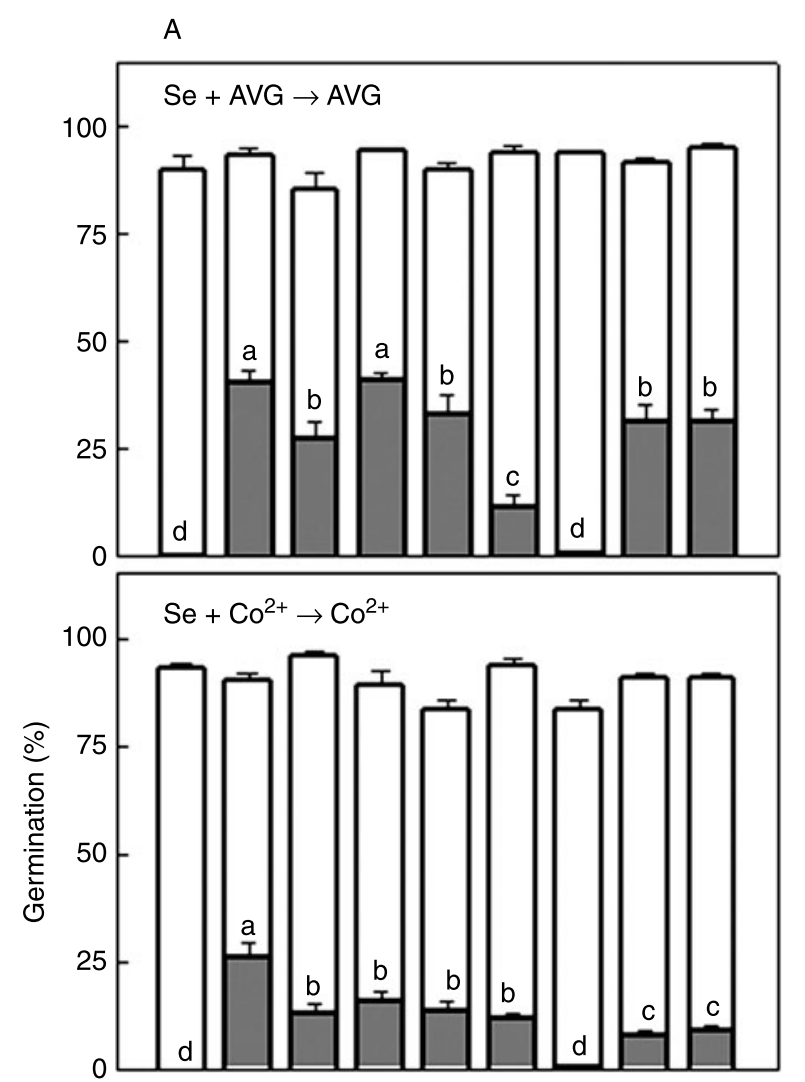

B
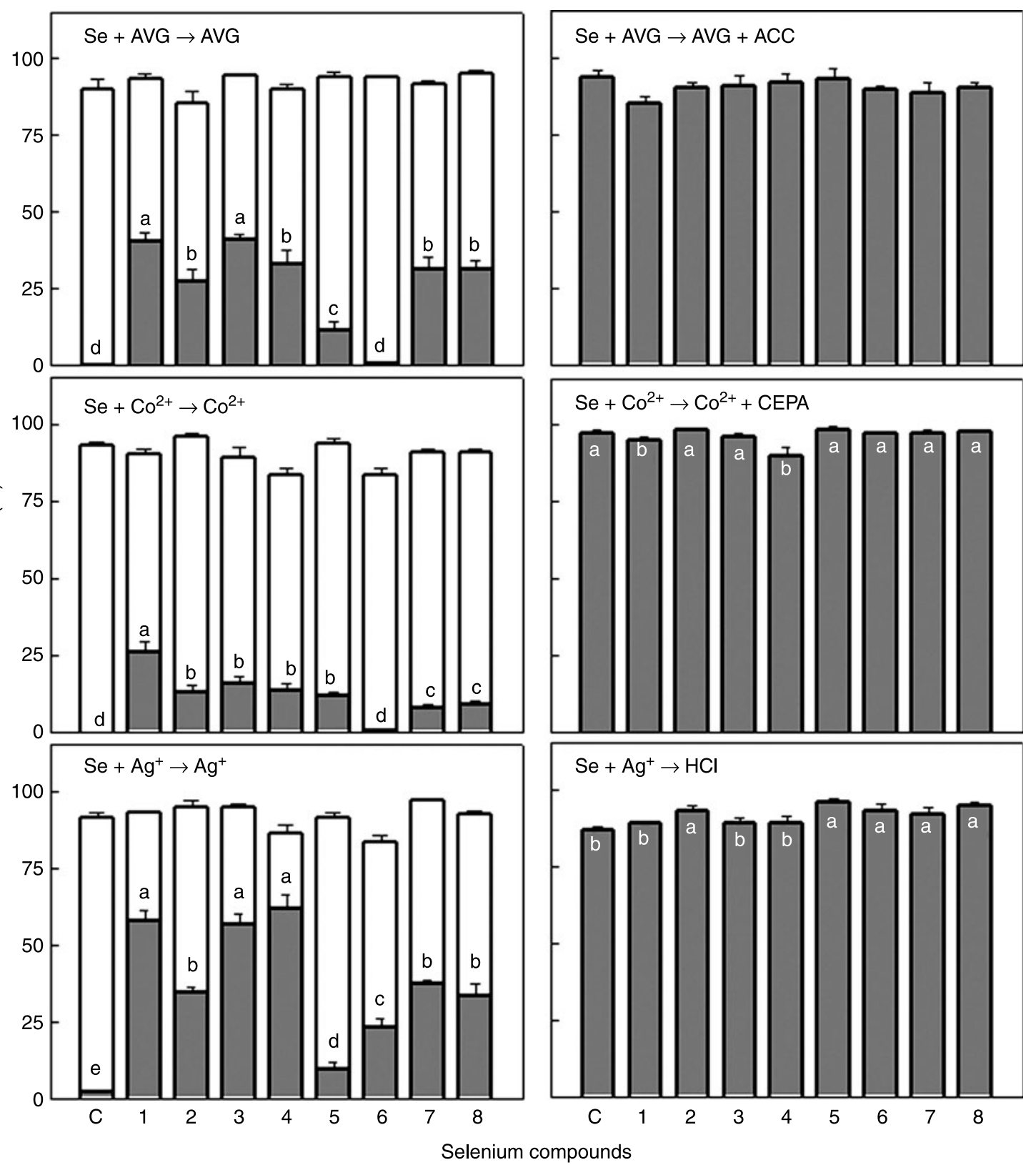

Figure 2. (A) Effects of anti-ethylenic substances on Se-stimulated dormant Stylosanthes humilis seeds in $9 \mathrm{~cm}$ diameter Petri dishes (responses shown in dark boxes). At the fifth day, solutions were replaced by thiourea to assess for seed viability (white boxes). (B) Reversal of the effects of anti-ethylenic compounds on Se-stimulated germination. Means of five replicates \pm SE. C, untreated dormant control; 1 , sodium selenate $\left(\mathrm{Na}_{2} \mathrm{SeO}_{4}\right)$; 2 , sodium selenite $\left(\mathrm{Na}_{2} \mathrm{SeO}_{3}\right) ; 3$, selenic acid $\left(\mathrm{H}_{2} \mathrm{SeO}_{4}\right) ; 4$, selenious acid $\left(\mathrm{H}_{2} \mathrm{SeO}_{3}\right) ; 5$, selenourea (SeU); 6, seleno-L-methionine $(\mathrm{SeM}) ; 7$, selenium tetrachloride $\left(\mathrm{SeCl}_{4}\right) ; 8$, selenium dioxide $\left(\mathrm{SeO}_{2}\right)$.

the greatly diverse chemical and physical properties of the Se compounds, leading to different uptake rates by the seeds, transport, metabolism and final action of the compounds (Läuchli, 1993).

Ethylene is required for germination of Townsville stylo seeds (Ribeiro and Barros, 2004, 2006), and it is likely that Se compounds break seed dormancy through eliciting ethylene biosynthesis by the seeds, as has been suggested by Barros and Freitas (2000, 2001) for SeM. All the rates of ethylene production were much larger in Se-treated seeds than in the dormant control seeds (Table 1), which also kept a 
tight relationship with the timing of the germination process (Fig. 1A); the start of germination coincided with a rapid increase in the rates of ethylene production. Since ACC breaks Townsville stylo seed dormancy (Vieira and Barros, 1994), the possibility remains that Se compounds had broken seed dormancy by eliciting ACC synthesis. Table 1 shows that the free ACC content was much higher after Se treatments than in untreated non-dormant seeds. The curves of ACC accumulation by Se-treated seeds correlated with the germination curves (Fig. 1B), suggesting a close relationship between the two phenomena. Similarly, the increases in ACC content lagged behind those of non-dormant untreated seeds. As in several other tissues, the amount of conjugated ACC greatly surpassed that of the free form in both Setreated and untreated seeds (Fig. 1B and Table 1). Like ethylene, ACC accumulation started earlier in SeUtreated seeds than in $\mathrm{H}_{2} \mathrm{SO}_{3}$-treated seeds, showing also the different timing for ACC biosynthesis and accumulation by Se-treated seeds (Fig. 1B). In summary, Se compounds break dormancy of Townsville stylo seeds, possibly by triggering ethylene biosynthesis via the ACC route. However, total ACC produced did not fully correlate with ethylene production. Hence, additional factors might be involved in controlling the germination process of Se-treated seeds.

SeM stimulates ethylene biosynthesis in mature flower buds of morning glory (Ipomea tricolor), constituting a substrate as efficient as methionine (Met) for the Met-adenosyltransferase. Both amino acids contribute the carbon atoms for ethylene formation. Moreover, these amino acids compete with each other as substrates for that enzyme (Konze et al., 1978; Konze and Kende, 1979). By contrast, while SeM broke dormancy of Townsville stylo seeds, methionine did not; the latter also did not affect the SeM-elicited dormancy breakage at all (Barros and Freitas, 2000, 2001). Therefore, in the process of dormancy breakage, SeM was not just providing the carbon atoms for ethylene formation. This was an expected result, since all other soluble Se-compounds tested broke dormancy (Table 1). Selenium is a toxic element at the concentrations used in this work (Terry et al., 2000; and see Materials and methods). This was likely to have led to a stress condition that could have elicited the activation or synthesis of an ACC synthase isoform, as occurs with several other stress elicitors (Pech et al., 2004). This might have been the case, since ACC amounts increased strongly upon Se treatments (Fig. 1), and a lack of ACC in dormant seeds seems to constitute a limiting step in dormancy breakage of Townsville stylo seeds. Typically, free ACC values were $3.6,19$ and 73 pmol seed $^{-1}$ in non-dormant seeds, and 0, 2.2 and $3.0 \mathrm{pmol} \mathrm{seed}^{-1}$ in dormant seeds, after 6, 12 and $18 \mathrm{~h}$ of imbibition, respectively (Pelacani and Barros, unpublished).

The involvement of ethylene in dormancy breakage and germination of Se-treated seeds was examined with the employment of anti-ethylenic substances. Germination of Se-treated seeds was substantially reduced by $\mathrm{AVG}$ and $\mathrm{Co}^{2+}$, inhibitors of ACC synthase (Babiker et al., 1994) and ACC oxidase (Gallardo et al., 1994), respectively, or by $\mathrm{Ag}^{+}$, an inhibitor of ethylene action (Fig. 2A). In some cases, inhibition of germination was complete. Restoration of germination to levels higher than $90 \%$ occurred when ACC was supplied simultaneously with AVG, CEPA simultaneously with $\mathrm{Co}^{2+}$, and $\mathrm{HCl}$ following $\mathrm{Ag}^{+}$ treatment, to precipitate the silver ions (Fig. 2B). Thus, impairment of ethylene biosynthesis and action greatly reduced or blocked the response of Se-treated seeds.

In conclusion, Se triggered an increase of ACC synthase activity (or stimulated the synthesis of an ACC synthase isoform), leading to the observed ACC accumulation in seed tissues. This constituted a key step in ethylene production that may be associated with the relief of dormancy and the germination of Townsville stylo seeds.

\section{Acknowledgements}

We are indebted to the Brazilian Council for Advancement of Science and Technology (CNPq), the Committee for Research Training at PostGraduate Level (CAPES), and the Foundation for Research Support of Minas Gerais State (FAPEMIG), for awarding scholarships to T.G.C., F.J.A.P. and B.M.L.S., respectively. R.S.B. held a fellow researcher position at CNPq. A research grant was also provided by FAPEMIG during the course of the present work.

\section{References}

Babiker, A.G.T., Cai, T., Ejeta, G., Butler, L.G. and Woodson, W.R. (1994) Enhancement of ethylene biosynthesis and germination with thidiazuron and some selected auxins in Striga asiatica seeds. Physiologia Plantarum 91, 529-536.

Ballard, L.A.T. and Buchwald, T. (1971) A viability test for seeds of Townsville stylo using thiourea. Australian Journal of Experimental Agriculture and Animal Husbandry 11, 207-210.

Barros, R.S. and Freitas, A.W.D. (2000) Stimulation of germination of dormant seeds of Townsville stylo by selenomethionine. Seed Science and Technology 28, 241-247.

Barros, R.S. and Freitas, A.W.D. (2001) Selenomethionine as a dormancy-breaking agent in seeds of Stylosanthes humilis. Acta Physiologiae Plantarum 23, 279-284. 
Gallardo, M., De Rueda, P.M., Matilla, A.J. and SánchezCalle, I.M. (1994) The relationships between ethylene production and germination of Cicer arietinum seeds. Biologia Plantarum 36, 201-207.

Konze, J.R. and Kende, H. (1979) Interactions of methionine and selenomethionine with methionine adenosyltransferase and ethylene-generating systems. Plant Physiology 63, 507-510.

Konze, J.R., Schilling, N. and Kende, H. (1978) Enhancement of ethylene formation by selenoamino-acids. Plant Physiology 62, 397-401.

Läuchli, A. (1993) Selenium in plants: uptake, functions, and environmental toxicity. Botanica Acta 106, 455-468.

Lizada, M.C.C. and Yang, S.F. (1979) A simple and sensitive assay for 1-aminocyclopropane-1-carboxylic acid. Analytical Biochemistry 100, 140-145.

Mattoo, A.K., Baker, J.E. and Moline, H.E. (1986) Induction by copper ions of ethylene production in Spirodela oligorrhiza: Evidence for a pathway independent of 1-aminocyclopropane-1-carboxylic acid. Journal of Plant Physiology 123, 193-202.

Mattoo, A.K., Mehta, R.A. and Baker, J.E. (1992) Copperinduced ethylene biosynthesis in terrestrial (Nicotiana tabacum) and aquatic (Spirodela oligorrhiza) higher plants. Phytochemistry 31, 405-409.

Merck \& Co. (1989) Merck Index (11th edition). Rahway, New Jersey, Merck \& Co.

Pech, J-C., Latché, A. and Bouzayen, M. (2004) Ethylene biosynthesis. pp. 115-136 in Davies, P.J. (Ed.) Plant hormones: Biosynthesis, signal transduction, action (2nd edition). Dordrecht, Kluwer Academic.
Reid, M.S., Paul, J.L., Farhoomand, M.B., Kofranek, A.M. and Staby, G.L. (1980) Pulse treatments with the silver thiosulfate complex extend the vase life of cut carnations. Journal of the American Society for Horticultural Science 105, 25-27.

Ribeiro, D.M. and Barros, R.S. (2004) A technique devised for detecting the ethylene requirement for germination as illustrated with Stylosanthes humilis seeds. Seed Science and Technology 32, 863-866.

Ribeiro, D.M. and Barros, R.S. (2006) Sensitivity to ethylene as a major component in the germination of seeds of Stylosanthes humilis. Seed Science Research 16, 37-45.

Saltveit, M.E. and Yang, S.F. (1987) Ethylene. pp. 367-396 in Rivier, L.; Crozier, A. (Eds) Principles and practice of plant hormone analysis, Vol. 2. London, Academic Press.

Scott, A.J. and Knott, M. (1974) A cluster analysis method for grouping means in the analysis of variance. Biometrics 30, 507-512.

Terry, N., Zayed, A.M., de Souza, M.P. and Tarun, A.S. (2000) Selenium in higher plants. Annual Review of Plant Physiology and Plant Molecular Biology 51, 401-432.

Vieira, H.D. and Barros, R.S. (1994) Responses of seed of Stylosanthes humilis to germination regulators. Physiologia Plantarum 92, 17-20.

Received 29 May 2007

accepted after revision 27 November 2007 (C) 2008 Cambridge University Press 